\title{
Mechanically Strong and Electrochemically
}

\section{Stable Single-Ion Conducting Polymer}

\section{Electrolytes Constructed from Hydrogen}

\section{Bonding}

Huihui Gan, Shaoqiao Li, Yong Zhang, Liping Yu, Jirong Wang, and Zhigang Xue*

Key Laboratory of Material Chemistry for Energy Conversion and Storage, Ministry of

Education, Hubei Key Laboratory of Material Chemistry and Service Failure, School of Chemistry and Chemical Engineering, Huazhong University of Science and Technology, Wuhan 430074, China.

E-mail address: zgxue@mail.hust.edu.cn (Z.Xue)

Number of pages: 5

Number of figures: 11

\section{Table of Contents}

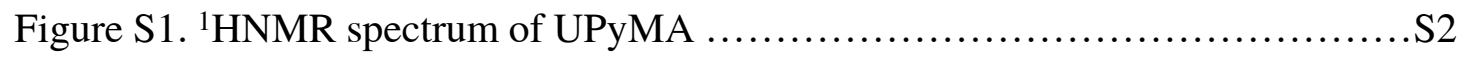

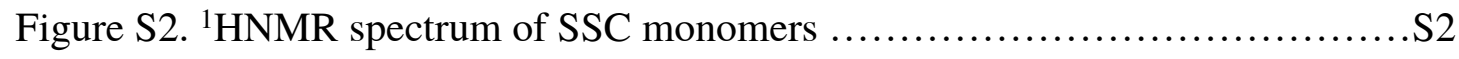

Figure S3. ${ }^{1} \mathrm{HNMR}$ spectrum of SSPSILi monomers........................... 2

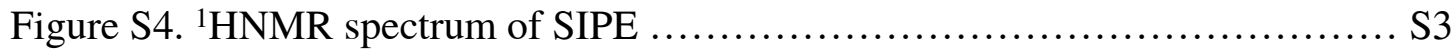


Figure S5. FT-IR spectra of monomers and copolymer.

Figure S6. Optical images of composite membranes..........................S3

Figure S7. Stress-strain curve of gel composite membrane .................... S4

Figure S8. Contact angle of composite membranes .........................S4

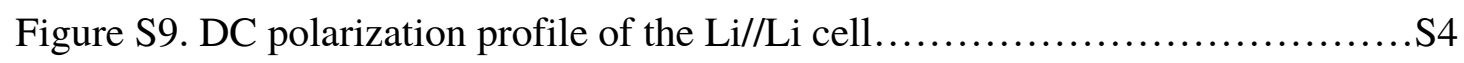

Figure S10. Voltage profiles for the $\mathrm{Li} / / \mathrm{Li}$ cell ................................ 5

Figure S11. Charge/discharge curves of the Li//LFP cell .......................S5

Figure S12. Charge/discharge curves of the Li//LFP cell ........................S5

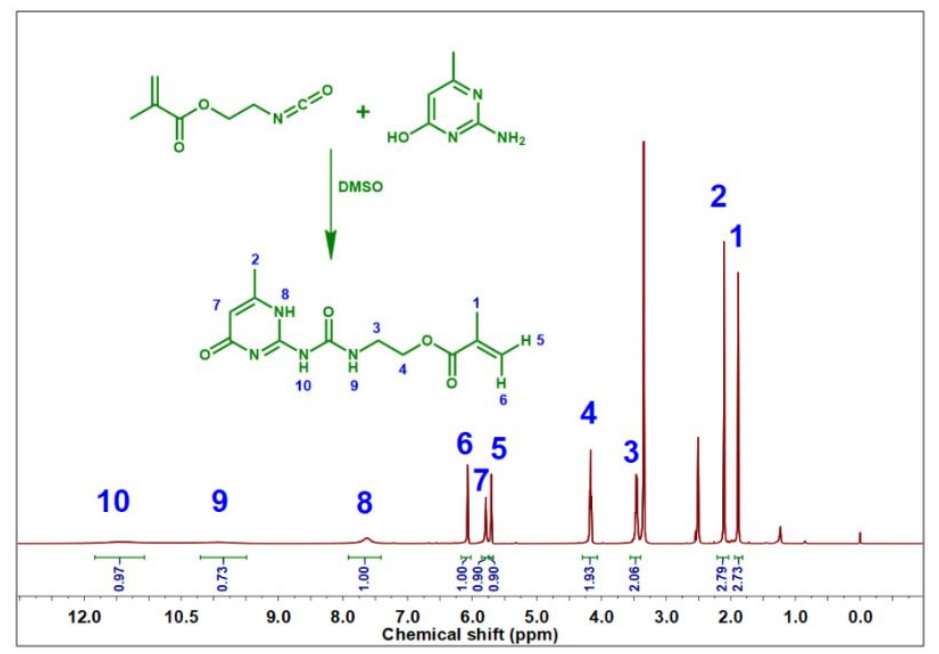

Figure S1. ${ }^{1}$ HNMR spectrum of UPyMA monomers (DMSO- $d_{6}$ ).

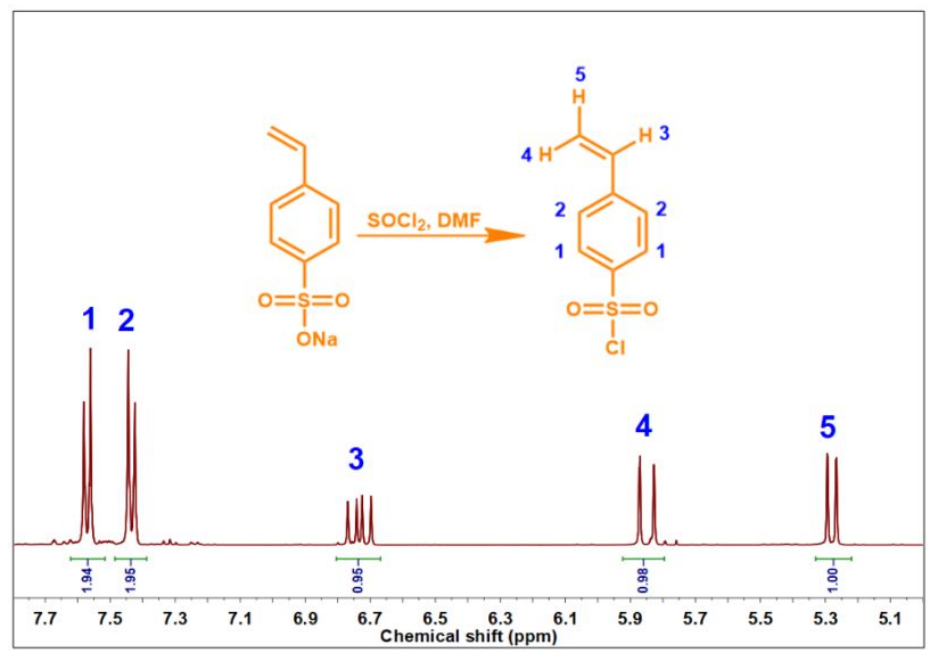


Figure S2. ${ }^{1} \mathrm{HNMR}$ spectrum of SSC monomers (DMSO- $d_{6}$ ).

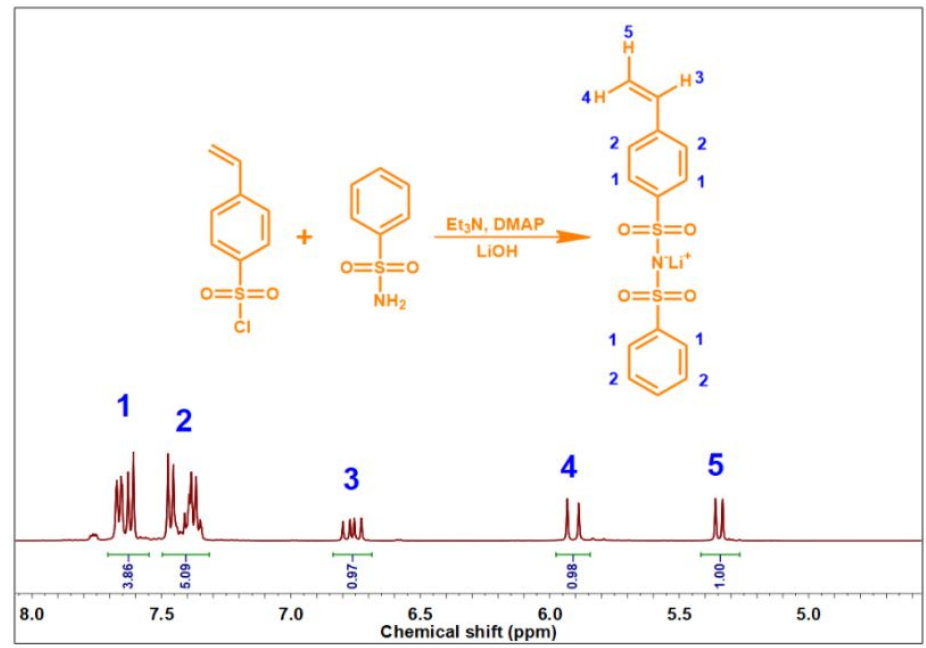

Figure S3. ${ }^{1} \mathrm{HNMR}$ spectrum of SSPSILi monomers (DMSO- $d_{6}$ ).

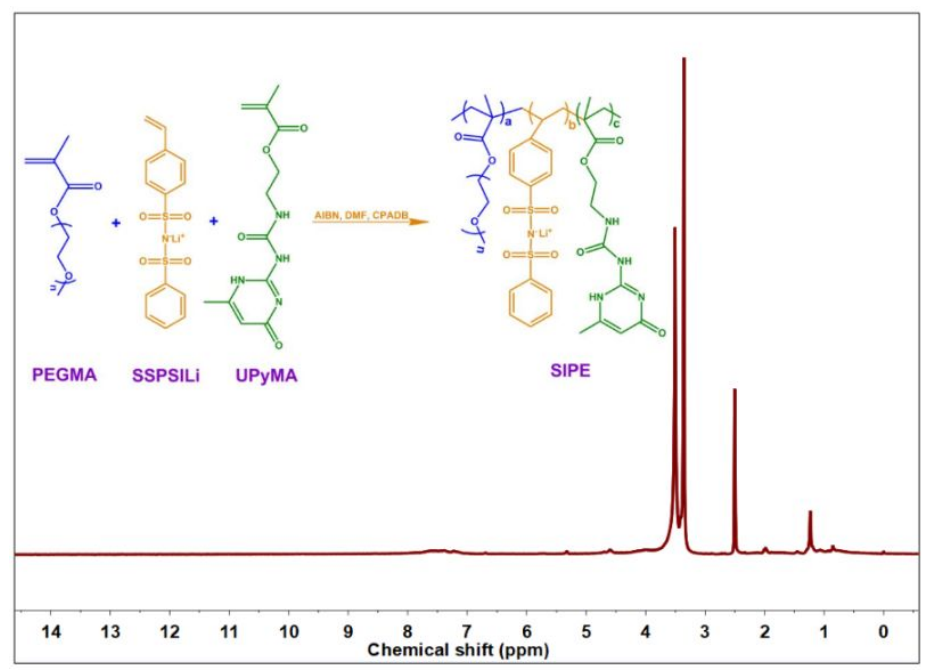

Figure S4. ${ }^{1} \mathrm{HNMR}$ spectrum of SIPE (DMSO- $d_{6}$ ). 


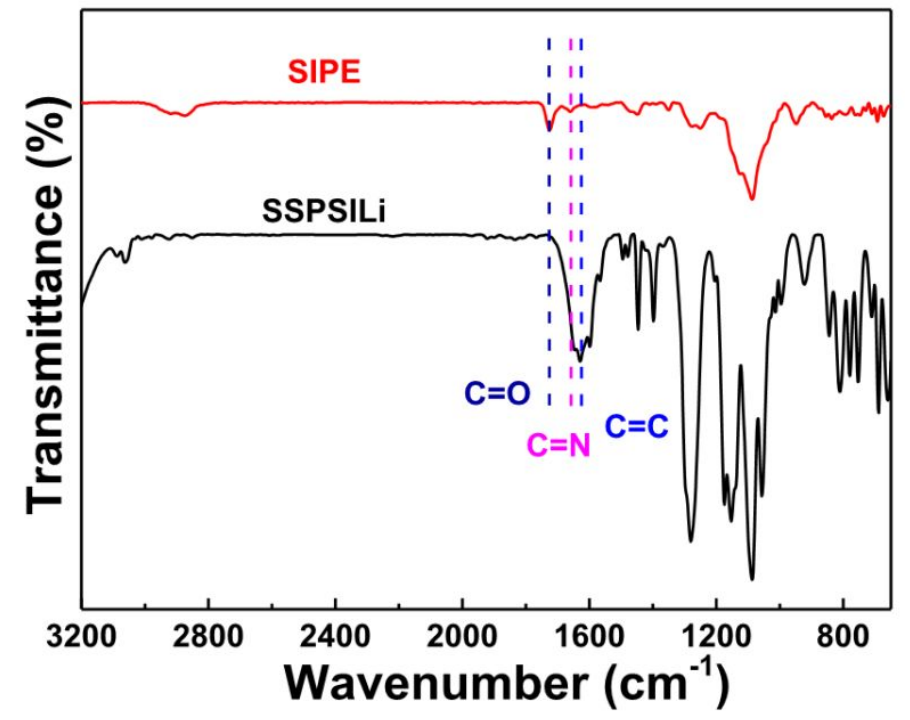

Figure S5. FT-IR spectra of SSPSILi monomers and SIPE copolymer.

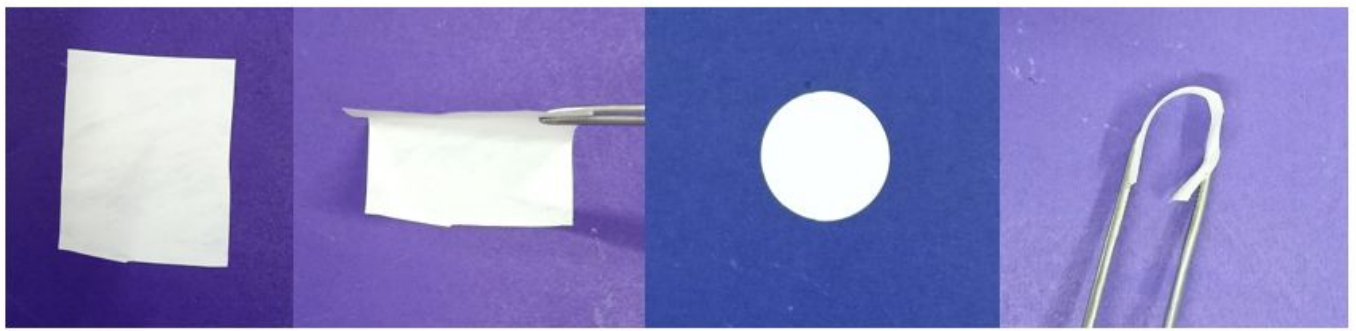

Figure S6. Optical images of composite membranes with $10 \mathrm{wt} \%$ of SIPE.

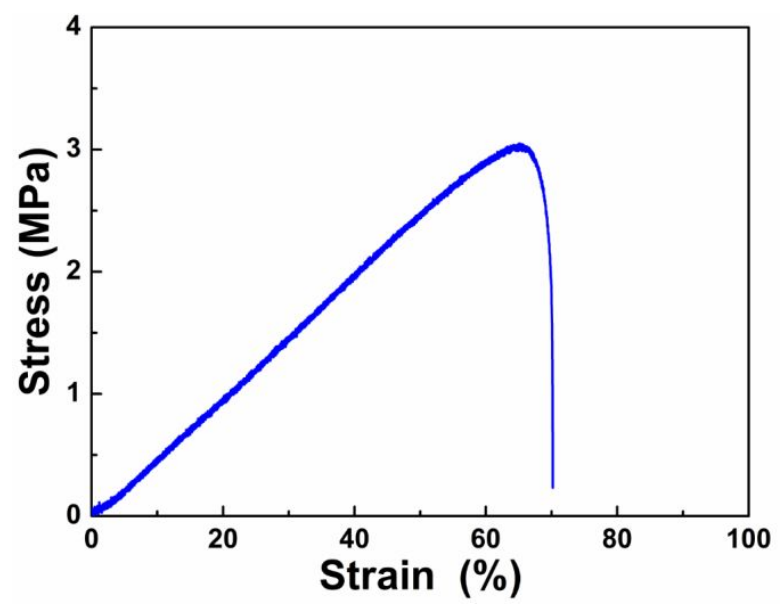


Figure S7. Stress-strain curve of $10 \mathrm{wt} \%$ of SIPE in composite membrane with PC solution (gel composite membrane).

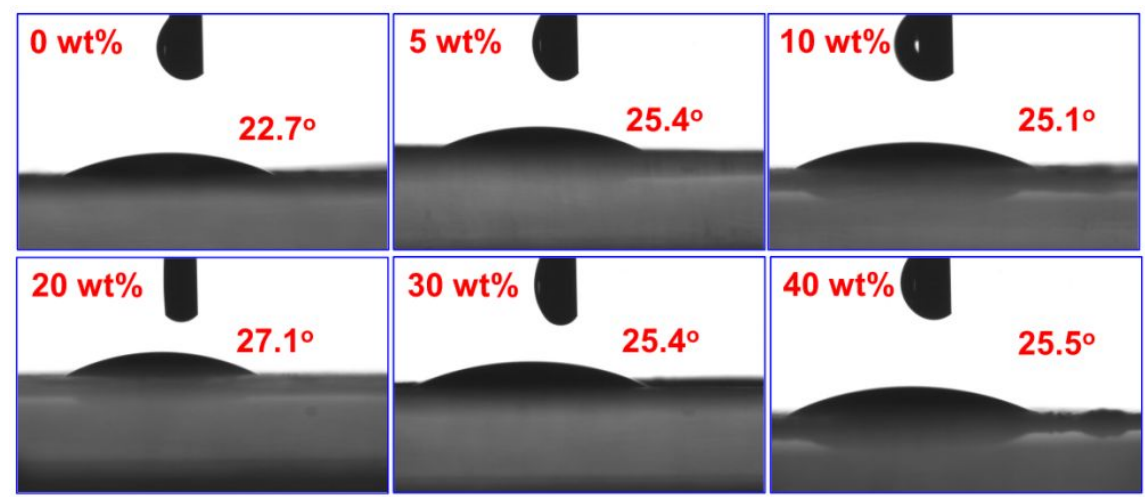

Figure S8. Contact angle photographs of SIPE/PVDF-HFP composite membranes.

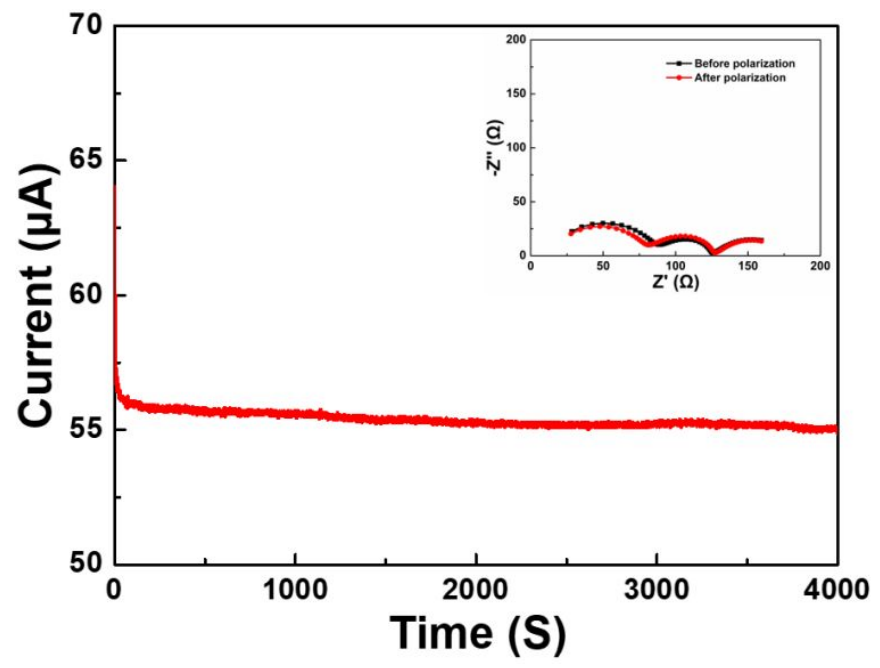

Figure S9. DC polarization profile of the Li symmetrical cell with $10 \mathrm{wt} \%$ SIPE gel composite membrane under a $10 \mathrm{mV}$ potential at $60{ }^{\circ} \mathrm{C}$ and the inset shows the $\mathrm{AC}$ impedance plots of the Li/SIGPE/Li symmetrical cell before and after polarization. 


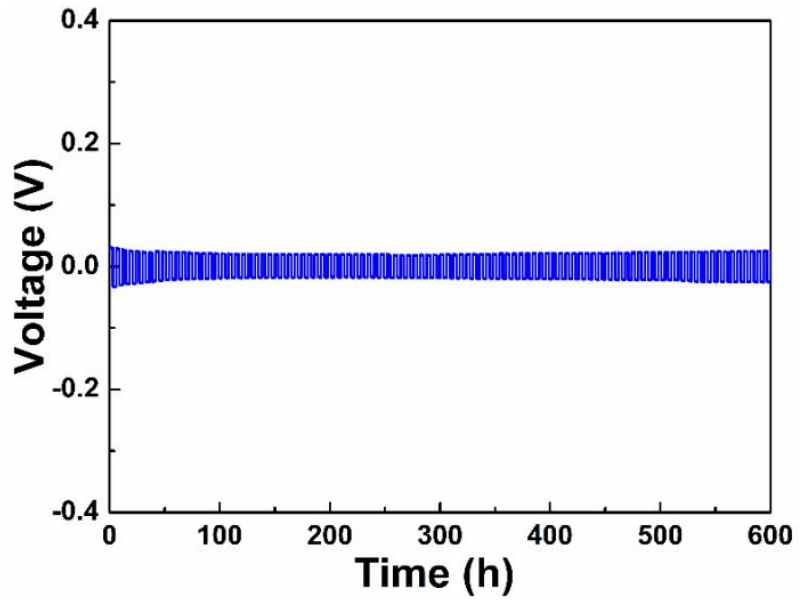

Figure S10. Voltage profiles for galvanostatic charge/discharge of the Li symmetric cell with composite membrane with $10 \mathrm{wt} \%$ of SIPE at current density of $0.10 \mathrm{~mA} \mathrm{~cm} \mathrm{~cm}^{-2}$ at $60^{\circ} \mathrm{C}$.

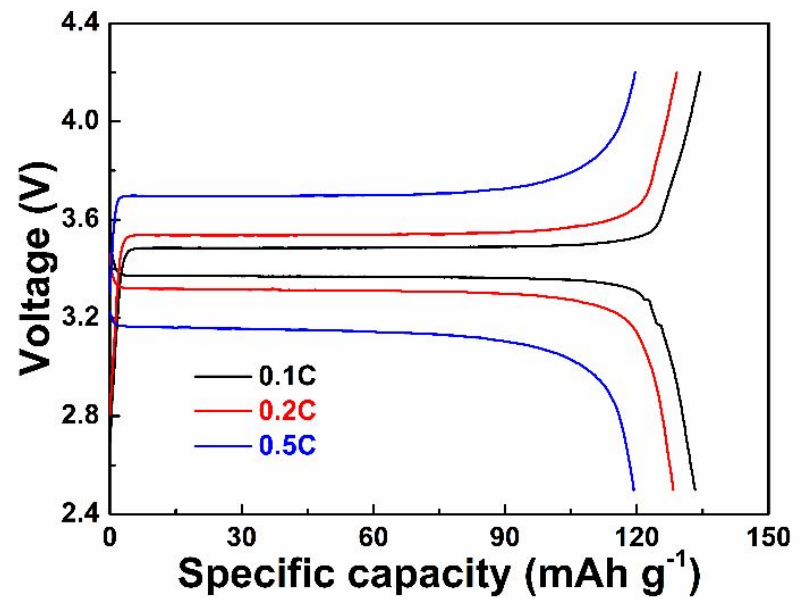

Figure S11. Charge/discharge curves of composite membrane with $10 \mathrm{wt} \%$ of SIPE at $0.1 \mathrm{C}, 0.2 \mathrm{C}$ and $0.5 \mathrm{C}$ at $60^{\circ} \mathrm{C}$.
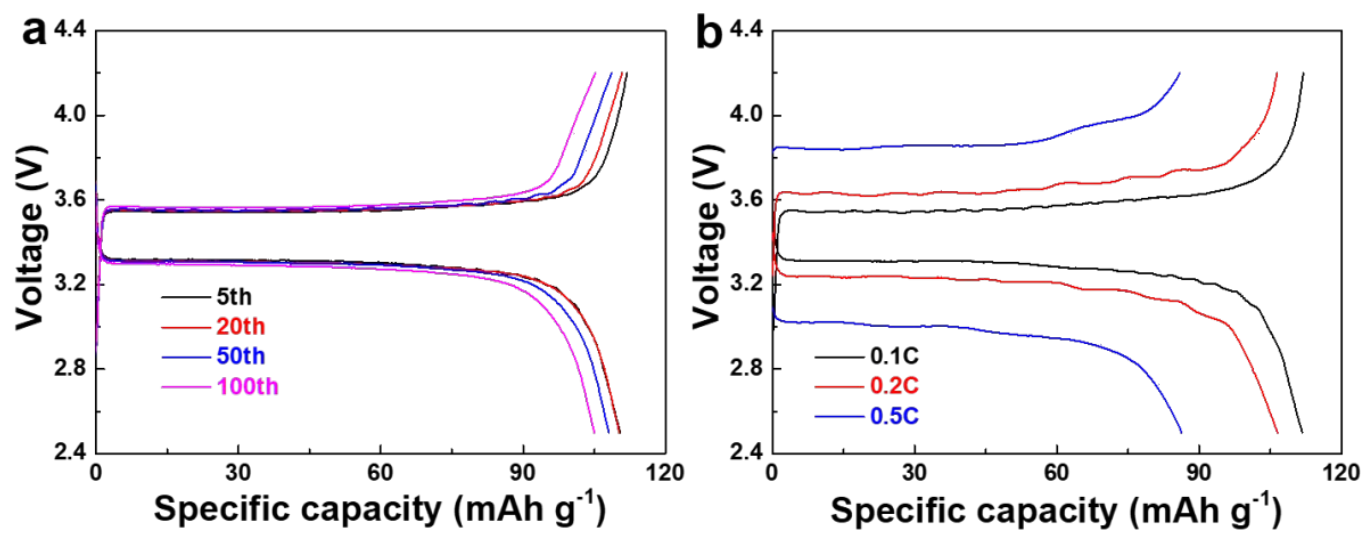
Figure S12. Charge/discharge curves of composite membrane with $10 \mathrm{wt} \%$ of SIPE at $25{ }^{\circ} \mathrm{C}$. (a) Different cycles at $0.1 \mathrm{C}$. (b) Different rates at $0.1 \mathrm{C}, 0.2 \mathrm{C}$ and $0.5 \mathrm{C}$. 